\title{
Treadmill exercise improves memory function by inhibiting hippocampal apoptosis in pilocarpine-induced epileptic rats
}

\author{
Jae-Min Lee', Eun-Sang Ji², Tae-Woon Kim², Chang-Ju Kim², Mal-Soon Shin ${ }^{3}$, Baek-Vin Lim', Yong-Rak Chung ${ }^{5}$, Young Sam Cho ${ }^{6, *}$ \\ 'Department of Pharmacology, School of Medicine, The Catholic University of Korea, Seoul, Korea \\ 2Department of Physiology, College of Medicine, Kyung Hee University, Seoul, Korea \\ ${ }^{3}$ School of Global Sport Studies, Korea University, Sejong, Korea \\ ${ }^{4}$ Division of Leisure \& Sports Science, Department of Exercise Prescription, Dongseo University, Busan, Korea \\ ${ }^{5}$ Department of Golf Mapping, College of Arts Physical Education, Joongbu University, Geumsan, Korea \\ ${ }^{6}$ Department of Urology, Kangbuk Samsung Hospital, Sungkyunkwan University School of Medicine, Seoul, Korea
}

Epilepsy is characterized by recurrent seizures and loss of neurons with abnormal rhythmic firing in the brains. In the present study, we investigated the effect of treadmill exercise on memory function in relation with cell proliferation and apoptosis in the hippocampus using pilocarpine-induced seizure rats. Epilepsy was initiated by intraperitoneal injection of pilocarpine hydrochloride. The rats in the exercise group were forced to run on a motorized treadmill for 30 min once a day for 2 weeks. In the present results, treadmill exercise alleviated short-term and spatial learning memory impairments in the epileptic rats. Treadmill exercise suppressed neuronal degeneration and enhanced neuronal maturation in the epileptic rats. Treadmill exercise suppressed cell proliferation and apoptosis in the epileptic rats. Treadmill exercise alleviated pilocarpine-induced memory impairments and suppressed neuronal loss in the hippocampus through down-regulation of apoptosis. These findings offer a possibility that treadmill exercise may provide a preventive or therapeutic value to the epilepsy-induced learning and memory impairments.

Keywords: Epilepsy, Treadmill exercise, Short-term memory, Spatial learning memory, Cell proliferation, Apoptosis

\section{INTRODUCTION}

Epilepsy is characterized by recurrent seizures and loss of neurons with abnormal rhythmic firing in the brain (Duncan et al., 2006). As memory function is affected by epilepsy, early and efficient control for seizure and prevention for brain damage from the beginning of epilepsy are demanded (Helmstaedter, 2002).

Neurogenesis is a process of generating functional neurons from progenitor cells, including proliferation, maturation, and functional integration into neuronal circuits (Ming and Song, 2005). Detection of 5-bromo-2'-deoxyuridine (BrdU) by immunohistochemistry has been used for phenotypic analysis and stereological quantification of newly formed neurons (Jin et al., 2017; Kim et al., 2017; Ming and Song, 2005). Newly generated neurons facilitate synaptic plasticity, which may be important for the formation of new memory (Jin et al., 2017; Schmidt-Hieber et al., 2004). Reduced cell proliferation in the hippocampal dentate gyrus impairs learning ability and memory function, in contrast, increased cell proliferation improves learning ability and memory function (Cho et al., 2017; Kim et al., 2017; Shin et al., 2013).

Excessive increase of cell proliferation in the hippocampal dentate gyrus has been observed in pathological states, such as seizure and ischemia (Jessberger et al., 2007; Lee et al., 2003; Parent et al., 2006; Sim et al., 2004). Kainic acid (KA)-induced seizure increased cell proliferation, and new neurons persisted for months after the seizure (Jessberger et al., 2007). Seizure-induced abnor-
${ }^{*}$ Corresponding author: Young Sam Cho (iD https://orcid.org/0000-0002-2966-7971 Department of Urology, Kangbuk Samsung Hospital, Sungkyunkwan University School of Medicine, 29 Saemunan-ro, Jongno-gu, Seoul 03181, Korea Tel: +82-2-2001-2237, Fax: +82-2-2001-2247, E-mail: choys1011@naver.com Received: August 12, 2018 / Accepted: September 5, 2018
This is an Open Access article distributed under the terms of the Creative Commons Attribution Non-Commercial License (http://creativecommons.org/licenses/by-nc/4.0/) which permits unrestricted non-commercial use, distribution, and reproduction in any medium, provided the original work is properly cited. 
mal migration of neuroblasts leads to abnormal integration of newborn cells into the hippocampal dentate gyrus, showing that aberrant neurogenesis is implicated in the progression of recurrent seizures (Parent et al., 2006). Up-regulation of cell proliferation has been thought as a compensatory response to lesion-induced excessive cell death (Lee et al., 2003; Sim et al., 2004).

Developing neurons express diverse markers during maturation process. Neuronal nuclear $(\mathrm{NeuN})$ antigen is considered as a specific marker of neurons, because it is not expressed in the non-neuronal cells (Wolf et al., 1996). Therefore, $\mathrm{NeuN}$ is regarded as the useful marker of neuronal maturation (Sarnat et al., 1998). Doublecortin (DCX) is a marker of neuronal precursor cells, and DCX is implicated in the neuronal migration and development (Friocourt et al., 2007; Kim et al., 2013).

Apoptosis is a process of programmed cell death and it is a part of a common mechanism in cell replacement, tissue remodeling, and the removal of damaged cells. Two important groups of proteins are involved in the apoptotic cell death. One is the members of the Bcl-2 family (Kuwana and Newmeyer, 2003) and the other is a class of cysteine proteases known as caspases (Cullen and Martin, 2009). The Bcl-2 family is classified into two functionally distinct groups: antiapoptotic proteins and pro-apoptotic proteins. $\mathrm{Bcl}-2$, an antiapoptotic protein, is known to regulate apoptotic pathways and protects against cell death. Bax, a pro-apoptotic protein of that family, is expressed abundantly and selectively during apoptosis and promotes cell death. Up-regulation of pro-apoptotic Bax and down-regulation of $\mathrm{Bcl}-2$ were observed in the pilocarpine-induced seizure (Zhang et al., 2013). Caspases, a family of 14 cysteine proteases, are essential players in apoptotic cell death both as initiators (caspase-2, -8, -9, and -10) and as executioners (caspase- $3,-6$, and -7) (Reed, 2000). Of these, caspase- 3 is one of the key executors of apoptosis (Benchoua et al., 2001). Terminal deoxynucleotidyl transferase-mediated dUTP nick end labeling (TUNEL) staining detects DNA fragmentation, one of the characteristics of apoptotic cell death (Baek and Kim, 2016; Doonan et al., 2013). Apoptosis has been suggested as one of the underlying mechanisms of the epileptic seizure (Méndez-Armenta et al., 2014; Xu et al., 2009; Zhang et al., 2013).

Exercise decreased seizure frequency as well as susceptibility to subsequently evoked seizure (Setkowicz and Mazur, 2006). Exercise exerted beneficial impact on neurocognitive and psychobehavioral function in children with benign epilepsy (Eom et al., 2014). In the present study, we investigated whether treadmill exercise exerts the protective effect against epilepsy-induced memory impairments. The effect of treadmill exercise on memory impairments was evaluated in relation with cell proliferation and apoptosis using pilocarpine-induced seizure rats.

\section{MATERIALS AND METHODS}

\section{Experimental animals}

Adult male rats $(250 \pm 10 \mathrm{~g})$ were used and the experimental procedures were performed in accordance with the animal care guidelines of the National Institutes of Health and the Korean Academy of Medical Sciences. The rats were divided into four groups ( $\mathrm{n}=10$ in each group): the control group, the control and treadmill exercise group, the pilocarpine injection group, and the pilocarpine injection and treadmill exercise group. Intraperitoneal injection of $50 \mathrm{mg} / \mathrm{kg}$ BrdU (Sigma Chemical Co., St. Louis, MO, USA) was performed to all of the rats, once a day $30 \mathrm{~min}$ before the starting of treatment during 4 days.

\section{Pilocarpine-induced epilepsy}

According to the previously described method (Blanco et al., 2009; Lim et al., 2015), epilepsy was initiated by intraperitoneal injection of $320 \mathrm{mg} / \mathrm{kg}$ pilocarpine hydrochloride (Sigma Chemical Co.). To minimize peripheral autonomic effect, scopolamine methyl nitrate (Sigma Chemical Co.) was injected 30 min prior to pilocarpine injection. The rats showing stage 4 or 5 convulsive seizure were considered as the epilepsy rats. In the case of continuing seizure for $60 \mathrm{~min}$, seizure was terminated by diazepam injection (10 mg/kg, Samjin, Seoul, Korea).

\section{Treadmill exercise protocol}

The rats in the exercise group were forced to run on a motorized treadmill for 30 min once a day for 2 weeks. The load of treadmill running consisted of running at $2 \mathrm{~m} / \mathrm{min}$ for the first of $5 \mathrm{~min}$, at $3 \mathrm{~m} / \mathrm{min}$ for the next $5 \mathrm{~min}$, and then at $5 \mathrm{~m} / \mathrm{min}$ for the last 20 min at 0 degree of inclination.

\section{Step-down avoidance task}

Short-term memory was determined using the step-down avoidance task, according to the previously described method (Jung and Kim, 2017; Kim et al., 2017). On the 14 days after starting experiment, the rats were trained with a step-down avoidance task. In the training session, the rats were placed on a $7 \times 25 \mathrm{~cm}$ platform, $2.5 \mathrm{~cm}$ in height. The platform faced a $42 \times 25 \mathrm{~cm}$ grid of parallel, $0.1 \mathrm{~cm}$-caliber stainless steel bars spaced $1 \mathrm{~cm}$ apart. The rats received $0.5 \mathrm{~mA}$ scramble foot shock for 2 sec immediately upon stepping down. Two hours after train- 
ing session, the latency (sec) of the animals was determined. Latency was the time interval of rats stepping down from platform and placing all four paws on the grid. Over 300 sec in latency was counted as $300 \mathrm{sec}$.

\section{Radial-arm maze task}

Spatial learning memory was determined using a radial 8-arm maze apparatus, according to the previously described method (Kim et al., 2017; Sim, 2014). The radial 8-arm maze apparatus consisted of a central octagonal plate $(30 \mathrm{~cm}$ in diameter) and radiating eight arms $(50 \mathrm{~cm}$ in length and $10 \mathrm{~cm}$ in width). The apparatus was placed $1 \mathrm{~m}$ above the floor. A small receptacle filled with water $(3 \mathrm{~cm}$ in diameter and $1 \mathrm{~cm}$ in depth) was located at the end of the arms. The rats were trained three times before the spatial learning memory test. In the training sessions, the rats deprived of water for $24 \mathrm{hr}$ were allowed to explore the water and to drink for $5 \mathrm{~min}$. During the test, the time spent in seeking water at the end of the arms was counted. The test was terminated when a rat found water in all eight arms or over 5 min elapsed. The number of correct choice before the first error was counted. Re-entering to the previously visited arms was counted as the error.

\section{Tissue preparation}

The rats were sacrificed immediately after last behavior test. After anesthetizing using Zoletil $50(10 \mathrm{mg} / \mathrm{kg}$, intraperitoneally; Vibac Laboratories, Carros, France), the rats were transcardially perfused with $50 \mathrm{mM}$ phosphate-buffered saline (PBS) and were fixed with $4 \%$ paraformaldehyde in $100 \mathrm{mM}$ phosphate buffer ( $\mathrm{PB}, \mathrm{pH}$ 7.4). The brains were dissected and post-fixed in the same fixative overnight and transferred into a $30 \%$ sucrose solution for cryoprotection. Using a freezing microtome (Leica, Nussloch, Germany), $40 \mu \mathrm{m}$ thick sagittal sections were made.

\section{BrdU Immunohistochemistry}

Immunohistochemistry for the BrdU-positive cells in the hippocampal dentate gyrus was performed, as the previously described method (Jung and Kim, 2017; Kim et al., 2017). The sections were permeabilized by incubating in $0.5 \%$ Triton X-100 in PBS for $20 \mathrm{~min}$, then they were pretreated in $50 \%$ formamide- $2 \times$ standard saline citrate at $65^{\circ} \mathrm{C}$ for $2 \mathrm{hr}$, denaturated in 2 $\mathrm{N} \mathrm{HCl}$ at $37^{\circ} \mathrm{C}$ for $30 \mathrm{~min}$, and they were rinsed twice in 100 $\mathrm{mM}$ sodium borate $(\mathrm{pH}, 8.5)$. Afterwards, the sections were incubated overnight at $4^{\circ} \mathrm{C}$ with BrdU-specific mouse monoclonal antibody (1:600; Roche, Mannheim, Germany). The sections were then washed three times with PBS and incubated for $1 \mathrm{hr}$ with the biotinylated mouse secondary antibody (1:200; Vector Laboratories, Burlingame, CA, USA). The sections were incubated for another $1 \mathrm{hr}$ with avidin-peroxidase complex (1:100; Vector Laboratories). For visualization, the sections were incubated for $5 \mathrm{~min}$ in $50 \mathrm{mM}$ Tris- $\mathrm{HCl}(\mathrm{pH}, 7.6)$ containing $0.02 \% 3,3^{\prime}$-diaminobenzidine (DAB), $40 \mathrm{mg} / \mathrm{mL}$ nickel chloride, and $0.03 \%$ hydrogen peroxide. The sections were finally mounted onto gelatin-coated slides. The slides were air-dried overnight at room temperature, and the coverslips were mounted using Permount (Thermo Fisher Scientific Inc., FairLawn, NJ, USA).

\section{Immunohistochemistry for NeuN, caspase-3, DCX}

Immunohistochemistry for NeuN, caspase-3, and DCX were performed, as the previously described method (Kim et al., 2017; Lee et al., 2016). Six sections on average were selected in each brain region spanning from Bregma $-2.50 \mathrm{~mm}$ to $-4.50 \mathrm{~mm}$. The sections were incubated overnight with mouse anti-NeuN antibody (1:500; EMD Millipore Corp., Billerica, MA, USA), rabbit anti-caspase-3 antibody (1:500; Santa Cruz Biotechnology, Santa Cruz, CA, USA), and mouse anti-DCX antibody (1:500; Santa Cruz Biotechnology), and then they were incubated for another 2 hr with the biotinylated secondary antibody (1:200; Vector Laboratories). The bound secondary antibody was then amplified using a Vector Elite $\mathrm{ABC}$ kit (Vector Laboratories). The antibody-biotin-avidin-peroxidase complex was visualized using $0.02 \% \mathrm{DAB}$. The sections were finally mounted onto gelatin-coated slides. The slides were air-dried overnight at room temperature, and the coverslips were mounted using Permount (Fisher Scientific).

\section{TUNEL staining}

According to the previous method (Baek and Kim, 2016; Kim et al., 2017), TUNEL staining was performed using the In situ Cell Death Detection Kit (Roche). Six sections on average were selected in each brain region spanning from Bregma $-2.50 \mathrm{~mm}$ to $-4.50 \mathrm{~mm}$. The sections were fixed in ethanol-acetic acid (2:1) and rinsed. The sections were then incubated with $100-\mu \mathrm{g} / \mathrm{mL}$ proteinase $\mathrm{K}$, rinsed, incubated in $3 \%$ hydrogen peroxide, permeabilized with $0.5 \%$ Triton X-100, rinsed again, and finally they were incubated in the TUNEL reaction mixture. The sections were rinsed and visualized using a Converter-POD with $0.02 \%$ DAB. Mayer's hematoxylin (DAKO, Glostrup, Denmark) was used for counter-staining and the sections were finally mounted onto gelatin-coated slides. The slides were air-dried overnight at room temperature, and the coverslips were mounted using Permount (Fisher Scientific). 

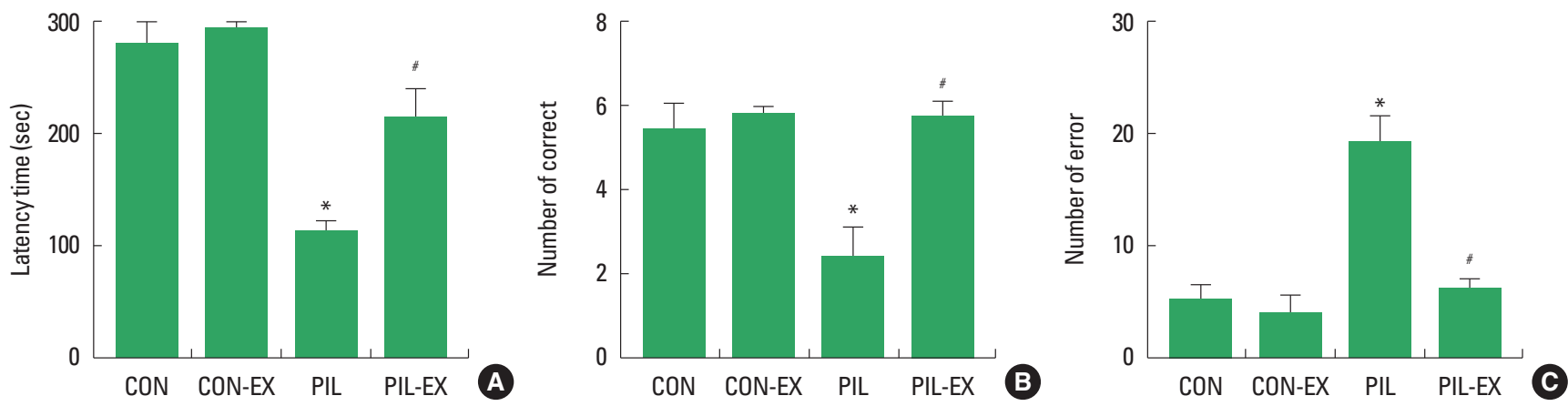

Fig. 1. Effects of treadmill exercise on short-term memory and spatial learning memory. (A) The latency time of the step-down avoidance task. (B) The number of correct choice before the first error of the radial-arm maze task. (C) The number of errors made before eight successful performances of the radial-arm maze task. CON, control group; CON-EX, control and treadmill exercise group; PIL, pilocarpine injection group; PIL-EX, pilocarpine injection and exercise group. ${ }^{*} P<0.05$ compared to the control group. ${ }^{\#} P<0.05$, compared to the pilocarpine-injection group.
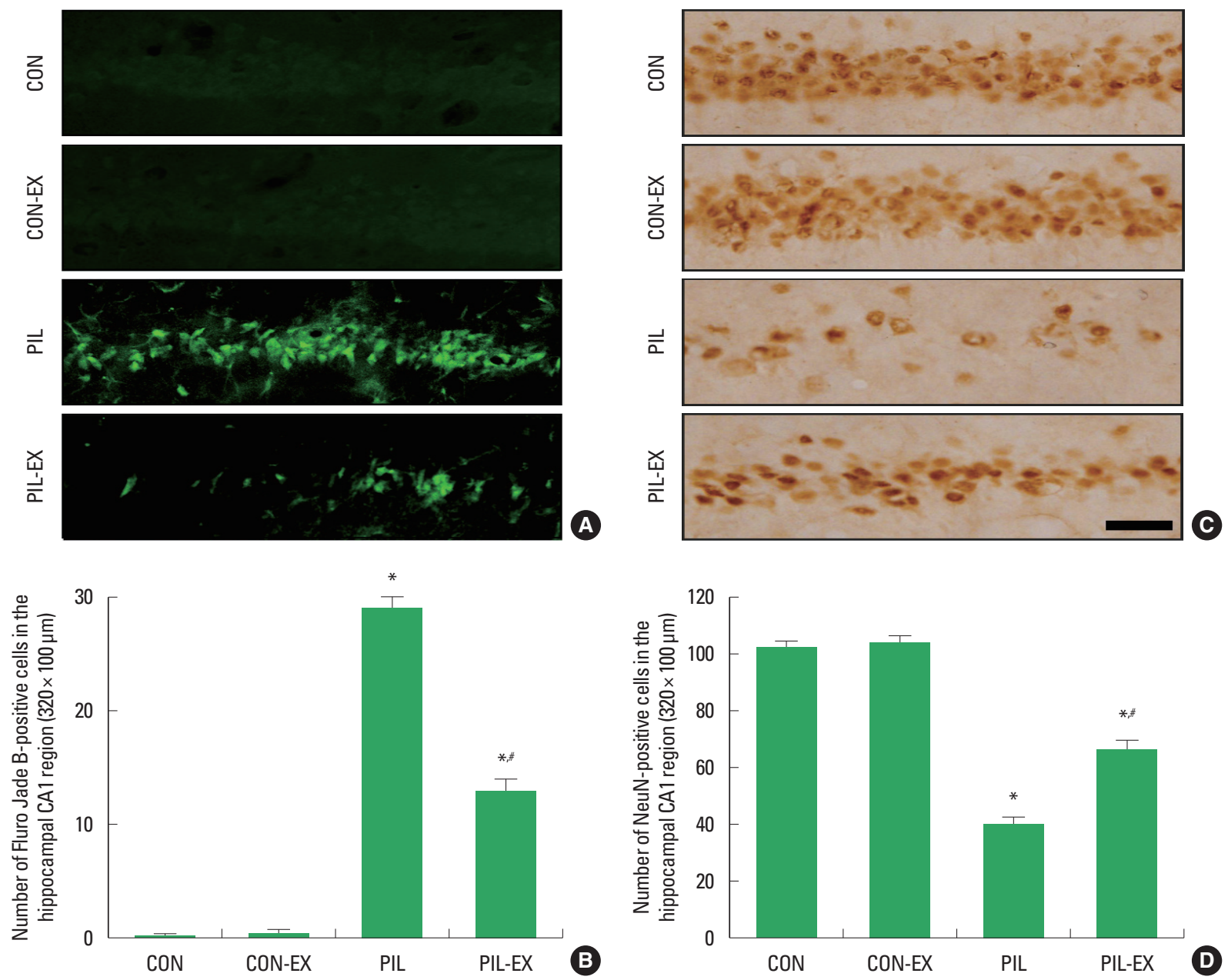

Fig. 2. Effect of treadmill exercise on neuronal degeneration and neuronal loss in the hippocampal CA1 region. (A) Photomicrographs of Fluoro-jade B-positive cells. (B) The number of Fluoro-jade B-positive cells in each group. (C) Photomicrographs of NeuN-positive cells. The scale bar represents $25 \mu \mathrm{m}$. (D) The number of NeuN-positive cells in each group. CON, control group; CON-EX, control and treadmill exercise group; PIL, pilocarpine injection group; PIL-EX, pilocarpine injection and exercise group. ${ }^{*} P<0.05$ compared to the control group. ${ }^{\sharp} P<0.05$, compared to the pilocarpine-injection group. 


\section{Fluoro-Jade B staining}

Fluoro-Jade B staining was carried out, as the previously described method (Kundrotiene et al., 2004; Scholl et al., 2013). The $40-\mu \mathrm{m}$ sections were mounted on coated slides and dried for $24 \mathrm{hr}$. The slides were rehydrated with descending ethanol-concentrations, washed for $2 \mathrm{~min}$ in distilled water, blocked in $0.06 \%$ potassium permanganate, and incubated for $30 \mathrm{~min}$ in the staining solution with $0.0008 \%$ Fluoro-Jade B (Histo-Chem Inc., Jefferson, AR, USA). Following staining, the slides were rinsed in distilled water, dried, and immersed in 100\% ethanol for $3 \mathrm{~min}$, in toluene for $3 \mathrm{~min}$, and mounted. The slides of the fluorescent images were captured using a confocal laser scanning microscopy (LSM-700; Carl Zeiss, München-Hallbergmoos, Germany).

\section{Western blot analysis}

Western blotting was performed, as the previously described method (Baek and Kim, 2016; Kim et al., 2017). Tissue samples
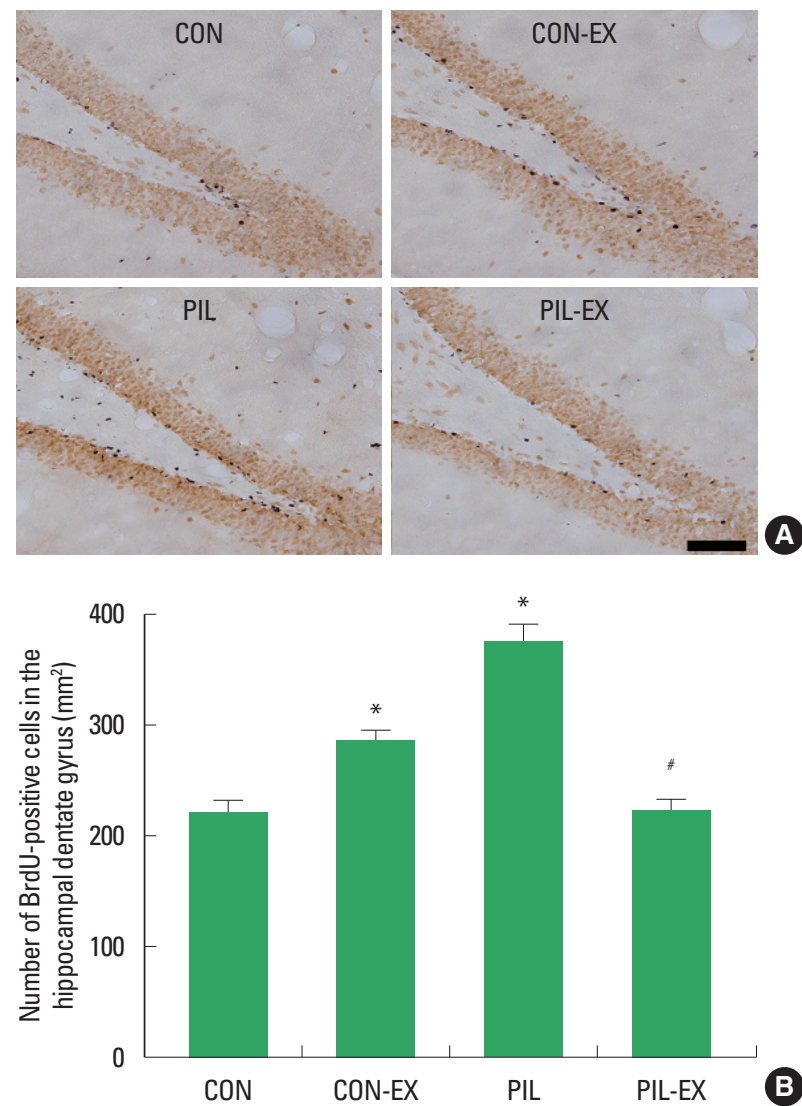

harvested from the hippocampus were lysed in the protein lysis buffer. Protein concentration was measured using a colorimetric protein assay kit (Bio-Rad, Hercules, CA, USA). Protein of $40 \mu \mathrm{g}$ was separated on sodium dodecyl sulfate-polyacrylamide gels and transferred onto a nitrocellulose membrane (Schleicher \& Schuell $\mathrm{GmbH}$, Dassel, Germany). Anti-mouse $\beta$-actin antibody (1:2,000; Santa Cruz Biotechnology), anti-mouse Bax antibody (1:1,000; Santa Cruz Biotechnology), anti-mouse Bcl-2 antibody (1:1,000; Santa Cruz Biotechnology) were used as the primary antibody. Horseradish peroxidase-conjugated anti-mouse antibodies (1:2,000; Santa Cruz Biotechnology) for $\beta$-actin, Bax, and Bcl-2 were used as the secondary antibody. Band detection was performed using as enhanced chemiluminescence detection system (Amersham Pharmacia Biotech GmbH, Freiburg, Germany).

\section{Statistical analysis}

The numbers of NeuN-positive and DCX-positive cells were
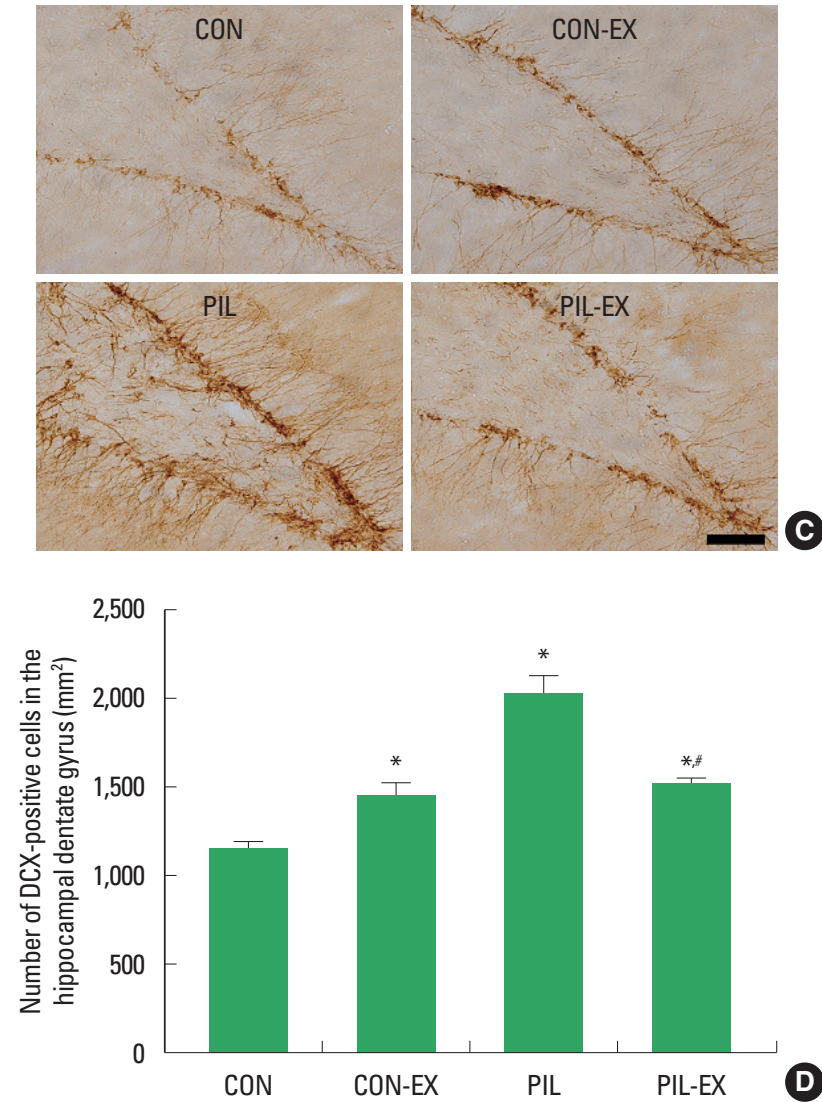

Fig. 3. Effect of treadmill exercise on cell proliferation in the hippocampal dentate gyrus. (A) Photomicrographs of 5-bromo-2'-deoxyuridine (BrdU)-positive cells. The scale bar represents $100 \mu \mathrm{m}$. (B) The number of BrdU-positive cells in each group. (C) Photomicrographs of doublecortin (DCX)-positive cells. The scale bar represents $100 \mu \mathrm{m}$. (D) The number of DCX-positive cells in each group. CON, control group; CON-EX, control and treadmill exercise group; PIL, pilocarpine injection group; PILEX, pilocarpine injection and exercise group. ${ }^{*} P<0.05$ compared to the control group. ${ }^{\sharp} P<0.05$, compared to the pilocarpine-injection group. 
counted hemilaterally under a light microscope (Olympus, Tokyo, Japan) and expressed as the numbers of cells per $\mathrm{mm}^{2}$ in the hippocampal dentate gyrus. The numbers of Fluro-Jade B-positive, TUNEL-positive, and caspase-3-positive cells were counted hemilaterally under a light microscope (Olympus) and expressed as the numbers of cells per $320 \times 100 \mu \mathrm{m}$ hippocampal CA1 region. The selected hippocampal area was measured by use of the Image- Pro Plus computer-assisted image analysis system (Media Cybernetics Inc., Silver Spring, MD, USA). To compare the relative expressions of Bax and Bcl-2, the detected bands were calculated densitometrically using Image-Pro Plus software (Media Cybernetics Inc.).

All data were analyzed using IBM SPSS Statistics ver. 21.0 (IBM Co., Armonk, NY, USA). The data were expressed as the mean \pm standard error of the mean. For the comparison among the groups, one-way analysis of variance and Duncan post hoc test were performed with $P<0.05$ as an indication of statistical significance.

\section{RESULTS}

\section{Latency of the step-down avoidance task}

The latency in the step-down avoidance task is presented in Fig. 1A. The present results showed that short-term memory was disturbed by pilocarpine-induced seizure. Treadmill exercise alleviated short-term memory impairments in the epileptic rats.

\section{Correct number and error number of the radial-arm maze task}

The number of correct choices is presented in Fig. 1B and the
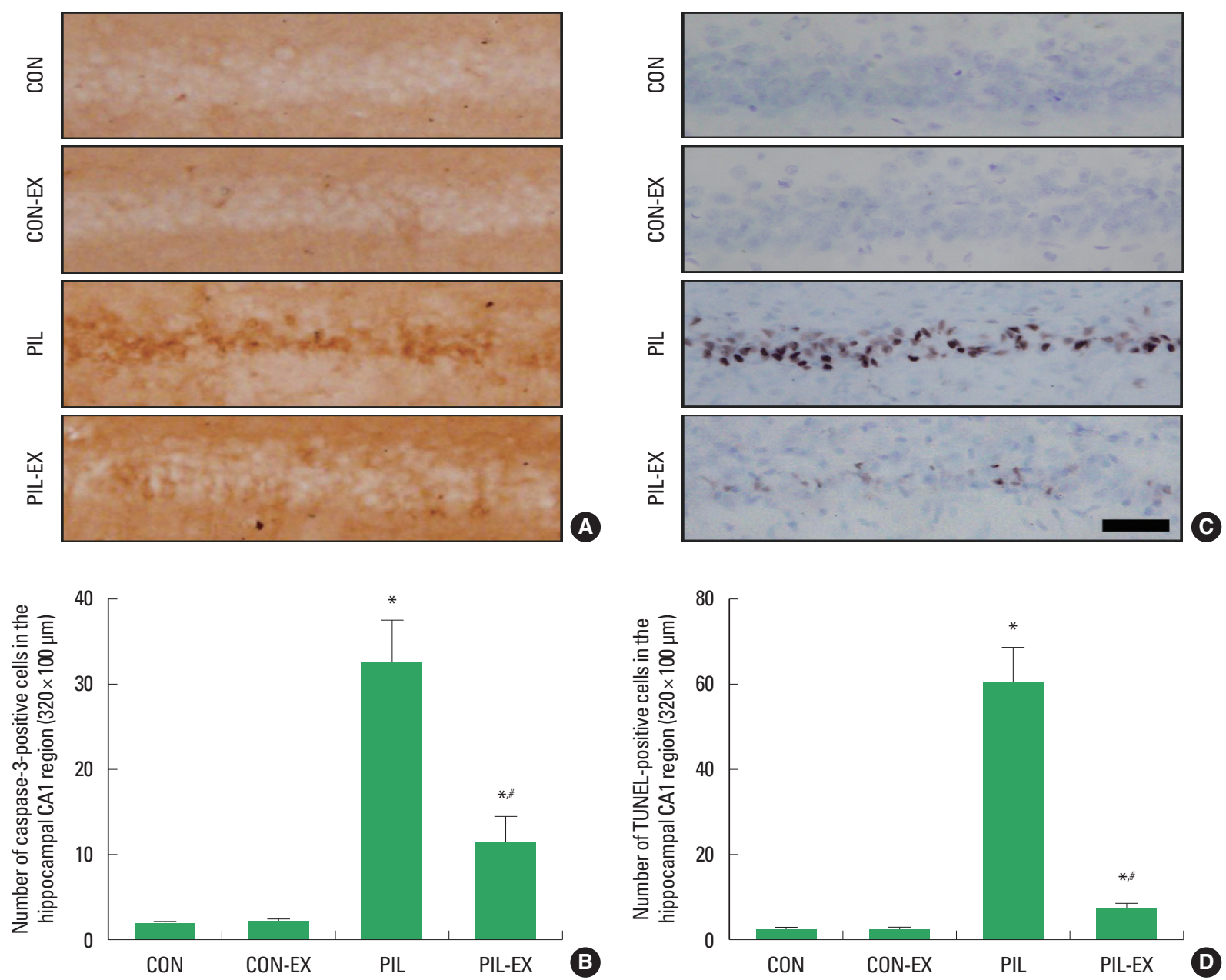

Fig. 4. Effect of treadmill exercise on apoptosis in the hippocampal dentate gyrus. (A) Photomicrographs of caspase-3-positive cells. (B) The number of caspase-3-positive cells in each group. (C) Photomicrographs of terminal deoxynucleotidyl transferase-mediated dUTP nick end labeling (TUNEL)-positive cells. The scale bar represents $25 \mu \mathrm{m}$. (D) The number of TUNEL-positive cells in each group. CON, control group; CON-EX, control and treadmill exercise group; PIL, pilocarpine injection group; PIL-EX, pilocarpine injection and exercise group. ${ }^{*} P<0.05$ compared to the control group. ${ }^{\sharp} P<0.05$, compared to the pilocarpine-injection group. 
number of error in the radial-arm maze task is presented in Fig. 1C. The present results showed that spatial learning memory was disturbed by pilocarpine-induced seizure. Treadmill exercise alleviated spatial learning memory impairments in the epileptic rats.

\section{Fluoro-Jade B-positive and NeuN-positive cells in the hippocampal CA1 region}

Photomicrographs of Fluoro-Jade B-positive cells in the hippocampal CA1 region are presented in Fig. 2A, B. Photomicrographs of NeuN-positive cells in the hippocampal CA1 region are presented in Fig. 2C, D. These results showed that neuronal de- generation was increased and neuronal maturation in the hippocampal CA1 region was decreased by pilocarpine-induced seizure. Treadmill exercise suppressed neuronal degeneration and enhanced neuronal maturation in the epileptic rats.

\section{BrdU-positive and DCX-positive cells in the hippocampal dentate gyrus}

Photomicrographs of BrdU-positive cells in the hippocampal dentate gyrus are presented in Fig. 3A, B. Photomicrographs of DCX-positive cells in the hippocampal dentate gyrus are presented in Fig. 3C, D. These results showed that cell proliferation in
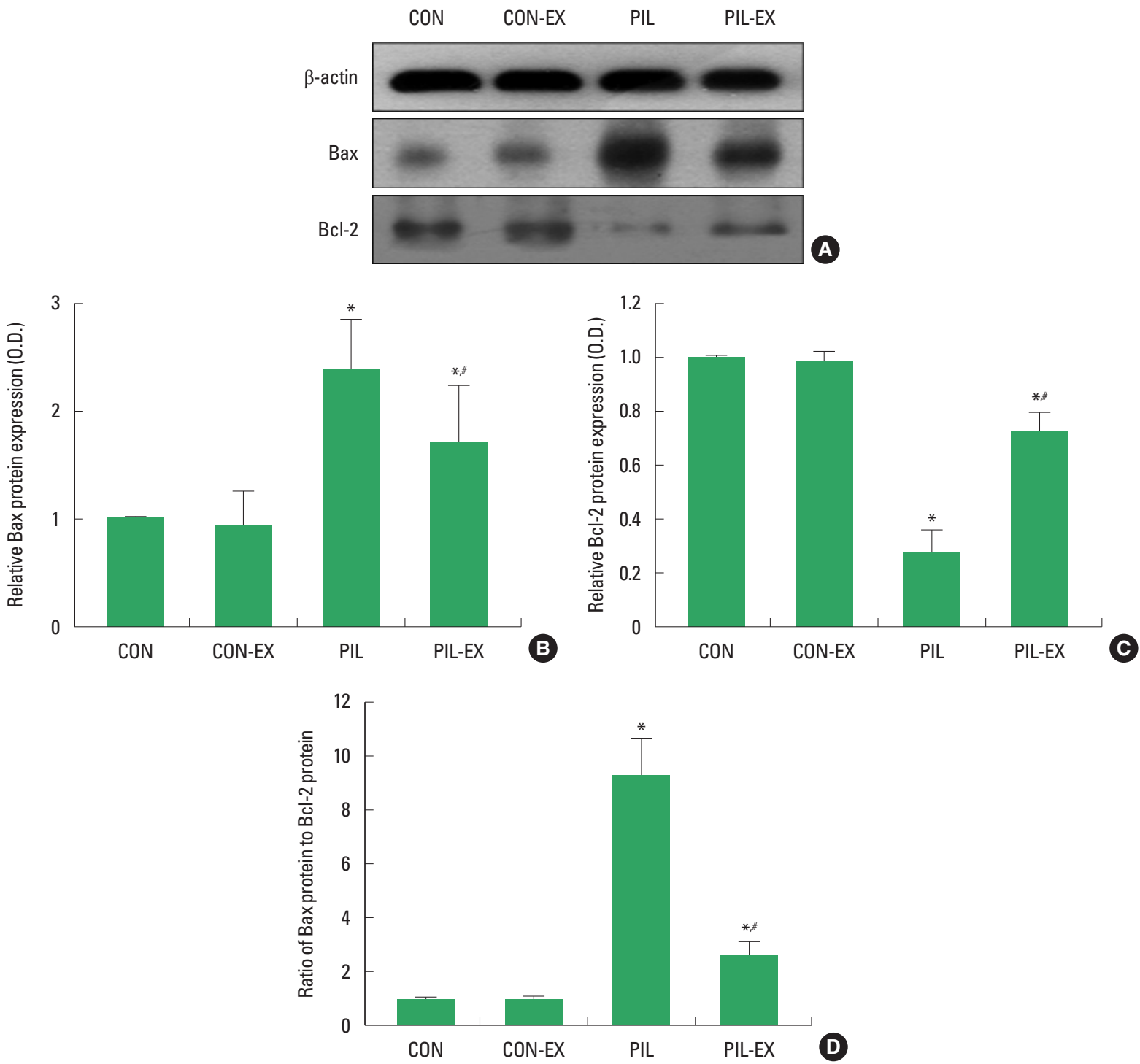

Fig. 5. Effects of treadmill exercise on Bax and Bcl-2 expressions in the hippocampus. (A) Representative Bax and Bcl-2 expressions in the hippocampus. (B) Relative Bax expression. (C) Relative Bcl-2 expression. (D) Ratio of Bax to Bcl-2. CON, control group; CON-EX, control and treadmill exercise group; PIL, pilocarpine injection group; PIL-EX, pilocarpine injection and exercise group. ${ }^{*} P<0.05$ compared to the control group. ${ }^{*} P<0.05$, compared to the pilocarpine-injection group. 
the hippocampal dentate gyrus region was increased by pilocarpine-induced seizure. Treadmill exercise suppressed cell proliferation in the epileptic rats.

\section{Caspase-3-positive and TUNEL-positive cells in the hippocampal CA1 region}

Photomicrographs of caspase-3-positive cells in the hippocampal CA1 region are presented in Fig. 4A, B. Photomicrographs of TUNEL-positive cells in the hippocampal CA1 region are presented in Fig. 4C, D. These results showed that apoptotic neuronal cell death in the hippocampal CA1 region was increased by pilocarpine-induced seizure. Treadmill exercise suppressed apoptotic neuronal cell death in the epileptic rats.

\section{Bax and $\mathrm{Bcl}-2$ expressions in the hippocampus}

Expressions of $\mathrm{Bax}$ and $\mathrm{Bcl}-2$ in the hippocampus are presented in Fig. 5. In the present results, Bax expression was increased and Bcl-2 expression in the hippocampus was decreased by pilocarpine-induced seizure. As a result, the ratio of $\mathrm{Bax}$ to $\mathrm{Bcl}-2$ was increased by pilocarpine-induced seizure. Treadmill exercise suppressed Bax expression and enhanced $\mathrm{Bcl}-2$ expression in the epileptic rats. As a result, the ratio of $\mathrm{Bax}$ to $\mathrm{Bcl}-2$ was decreased in the epileptic rats. These results showed that treadmill exercise inhibited apoptosis process in the epileptic rats.

\section{DISCUSSION}

Step-down avoidance task has been used for the determination of short-term memory (Jung and Kim, 2017; Kim et al., 2017) and radial 8-arm maze task is test for the evaluation of spatial learning memory (Kim et al., 2017; Sim, 2014). Many studies have reported that exercise is effective to improve memory function from diverse brain insults (Jung and Kim, 2017; Kim et al., 2013; Sim et al., 2004).

In the present results, short-term memory was impaired in the pilocarpine-induced epileptic rats. Spatial learning memory was also disturbed in the pilocarpine-induced epileptic rats. However, the rats performing treadmill exercise improved short-term memory and spatial learning memory deteriorated by pilocarpine-induced seizure. The present results showed that treadmill exercise ameliorated seizure-induced memory impairments.

Neuronal loss in the hippocampus following epileptic seizure is associated with memory loss (Helmstaedter, 2002). Neuronal loss in the hippocampus is a common feature of epilepsy (Thom et al., 2009). Reduced neurons in the hippocampal CA1 region is asso- ciated with memory and cognitive impairments (Zhang et al., 2013). Deficits in learning and memory following seizure have a close correlation with neuronal death in the hippocampal CA1 region (Tyler et al., 2012). Neuronal death by cortical compression-induced ischemia was detected by Fluoro-Jade staining (Kundrotiene et al., 2004). Fluoro-Jade B is a histochemical marker for degenerating neurons in the rat pups with status epilepticus (Scholl et al., 2013). NeuN, a specific marker of neuronal cells, recognizes nuclear proteins rather than cytoplasmic antigens or cytoplasmic organelles, and does not stain the nuclei of immature nerve cells. Thus, NeuN satisfies the primary criterion of a tissue marker regarding neuronal maturation (Sarnat et al., 1998). In the autoimmune encephalomyelitis mice, initial increment of the progenitor cells was appeared, however, succeeding differentiation of BrdU-positive cells into mature NeuN-positive neurons was delayed (Huehnchen et al., 2011). Lipopolysaccharide induced brain inflammation impaired short term memory by suppressing NeuN expression in the hippocampal dentate gyrus of rats (Kim et al., 2013). Treadmill exercise improved brain inflammation induced short term memory impairments by increasing NeuN expression, showing facilitation of neuronal maturation (Kim et al., 2013).

In the present results, the number of Fluoro-Jade-positive cells was increased and the number of NeuN-positive cells in the hippocampal CA1 region was decreased in the pilocarpine-induced epileptic rats. These results suggested that seizure initiated neuronal degeneration and disturbed neuronal maturation. However, the rats performing treadmill exercise showed decrement in the number of Fluoro-Jade-positive cells and increment in the number of NeuN-positive cells in the pilocarpine-induced epileptic rats. These results suggested that treadmill exercise inhibited neuronal degeneration and facilitated neuronal maturation in the epileptic rats.

Initial seizure induced ectopic precursor cell proliferation, resulting in the dispersion of immature neurons, which expressed DCX. Thus, seizure-generated neurons contribute to the epilepsy process (Jessberger et al., 2007). Seizure-induced abnormality of neuroblast migration leads to abnormal integration of newborn granule cells and aberrant neurogenesis is implicate in the development or progression of recurrent seizures (Parent et al., 2006). Such excessive cell proliferation has been ascribed to the compensatory response to excessive cell death (Lee et al., 2003; Sim et al., 2004). Treadmill exercise suppressed ischemia-induced cell proliferation in the hippocampal dentate gyrus and improved memory function (Lee et al., 2003; Sim et al., 2004). Treadmill exercise af- 
ter seizure also substantially reduced progenitor cell proliferation in the hippocampus. This inhibition of aberrant neurogenesis protected the animals from seizure-induced cognitive impairments in a hippocampus-dependent learning task (Jessberger et al., 2007).

In the present results, the numbers of BrdU-positive and DCX-positive cells in the hippcomapal dentate gyrus were increased by pilocarpine injection, However, the rats performing treadmill exercise showed decrement in the numbers of BrdU-positive and DCX-positive cells in the epileptic rats. These results suggested that seizure accelerated neurogenesis, in contrast, treadmill exercise inhibited seizure-induced neurogenesis in the hippocampal dentate gyrus.

Apoptotic cell death pathway is closely associated with seizure activity of epilepsy (Henshall and Simon, 2005). Caspase-3 contributed to the cell death occurring within the first week after status epilepticus in rats (Narkilahti et al., 2003). TUNEL-positivity and activated caspase- 3 expression were observed in the amygdala, piriform cortex, and hippocampal CA1 region, demonstrating that apoptosis contributed to neuronal cell death in the pilocarpine-induced status epilepticus (Weise et al., 2005). The number of TUNEL-positive cells in the hippocampus was increased in the pilocarpine-induced seizure rats (Liu et al., 2012). Pilocarpine-induced status epilepticus in the immature rat brain caused neuronal injury in several distinct areas outside of the hippocampus, showing similar to areas damaged in patients with temporal lobe epilepsy (Scholl et al., 2013). Oxidative stress induced apoptosis in the experimental model of epilepsy (Méndez-Armenta et al., 2014).

In the present results, the numbers of TUNEL-positive and caspase-3-positive cells in the hippocampal dentate gyrus were increased by pilocarpine injection, indicating that seizure facilitated apoptotic neuronal cell death in the hippocampal dentate gyrus. In contrast, treadmill exercise inhibited the numbers of TUNELpositive and caspase-3-positive cells in the epileptic rats, indicating that treadmill exercise reduced seizure-induced apoptosis.

The ratio of $\mathrm{Bcl}-2$ to Bax was decreased and caspase- 3 was activated in the pilocarpine-induced seizure rats (Xu et al., 2009). Reversal of Bcl-2 to Bax ratio and inhibition of caspase- 3 has therapeutic value for seizure (Xu et al., 2009). Higher level of Bcl-2 and lower level of Bax were associated with treatment of status epilepticus in rats (Jun et al., 2009). Activation of apoptosis-related factors increased Bax expression and decreased Bcl-2 expression during seizure (Zhang et al., 2013). Increasing the ratio of Bcl-2 to Bax and inhibiting caspase-3 activation exerted a neuroprotective effect through inhibition of apoptotic pathways in the status epilepticus rats (Zhang et al., 2013).

In the present results, $\mathrm{Bcl}-2$ expression was decreased and $\mathrm{Bax}$ expression was increased in the hippocampus by pilocarpine injection, resulting in an increment of Bax to Bcl-2 ratio. Treadmill exercise decreased Bax expression and increased $\mathrm{Bcl}-2$ expression in the epileptic rats, resulting in a decrement of $\mathrm{Bax}$ to $\mathrm{Bcl}-2$ ratio. The present results showed that seizure facilitated apoptotic process and treadmill exercise inhibited seizure-induced apoptotic process.

Physical exercise can ameliorate memory deficits induced by early-life status epilepticus (Córdova et al., 2013). Treadmill exercise prevented gamma-aminobutyric acid-ergic neuronal loss and inhibited neuronal activation in the hippocampal CA1 region through down-regulation of brain-derived neurotrophic factor-tyrosine kinase receptor B signaling pathway in the pilocarpine-induced epileptic rats (Lim et al., 2015).

In the present study, treadmill exercise alleviates pilocarpine-induced memory impairments and inhibited neuronal loss in the hippocampus through the down-regulation of apoptosis. These findings suggest a possibility that treadmill exercise may provide a preventive or therapeutic value to the epilepsy-induced learning and memory impairments.

\section{CONFLICT OF INTEREST}

No potential conflict of interest relevant to this article was reported.

\section{REFERENCES}

Baek SS, Kim SH. Treadmill exercise ameliorates symptoms of Alzheimer disease through suppressing microglial activation-induced apoptosis in rats. J Exerc Rehabil 2016;12:526-534.

Benchoua A, Guégan C, Couriaud C, Hosseini H, Sampaïo N, Morin D, Onténiente B. Specific caspase pathways are activated in the two stages of cerebral infarction. J Neurosci 2001;21:7127-7134.

Blanco MM, dos Santos JG Jr, Perez-Mendes P, Kohek SR, Cavarsan CF, Hummel M, Albuquerque C, Mello LE. Assessment of seizure susceptibility in pilocarpine epileptic and nonepileptic Wistar rats and of seizure reinduction with pentylenetetrazole and electroshock models. Epilepsia 2009;50:824-831.

Cho JW, Jung SY, Lee SW, Lee SJ, Seo TB, Kim YP, Kim DY. Treadmill exercise ameliorates social isolation-induced depression through neuronal generation in rat pups. J Exerc Rehabil 2017;13:627-633.

Córdova SD, Loss CM, de Oliveira DL. Low-intensity physical training 
recovers object recognition memory impairment in rats after early-life induced status epilepticus. Int J Dev Neurosci 2013;31:196-201.

Cullen SP, Martin SJ. Caspase activation pathways: some recent progress. Cell Death Differ 2009;16:935-938.

Doonan F, Cotter TG. Detection of DNA fragmentation in retinal apoptosis by TUNEL. Methods Mol Biol 2013;935:207-213.

Duncan JS, Sander JW, Sisodiya SM, Walker MC. Adult epilepsy. Lancet 2006;367:1087-1100.

Eom S, Lee MK, Park JH, Jeon JY, Kang HC, Lee JS, Kim HD. The impact of an exercise therapy on psychosocial health of children with benign epilepsy: a pilot study. Epilepsy Behav 2014;37:151-156.

Friocourt G, Liu JS, Antypa M, Rakic S, Walsh CA, Parnavelas JG. Both doublecortin and doublecortin-like kinase play a role in cortical interneuron migration. J Neurosci 2007;27:3875-3883.

Helmstaedter C. Effects of chronic epilepsy on declarative memory systems. Prog Brain Res 2002;135:439-453.

Henshall DC, Simon RP. Epilepsy and apoptosis pathways. J Cereb Blood Flow Metab 2005;25:1557-1572.

Huehnchen P, Prozorovski T, Klaissle P, Lesemann A, Ingwersen J, Wolf SA, Kupsch A, Aktas O, Steiner B. Modulation of adult hippocampal neurogenesis during myelin-directed autoimmune neuroinflammation. Glia 2011;59:132-142.

Jessberger S, Nakashima K, Clemenson GD Jr, Mejia E, Mathews E, Ure K, Ogawa S, Sinton CM, Gage FH, Hsieh J. Epigenetic modulation of seizure-induced neurogenesis and cognitive decline. J Neurosci 2007;27: 5967-5975.

Jin JJ, Ko IG, Kim SE, Hwang L, Lee MG, Kim DY, Jung SY. Age-dependent differences of treadmill exercise on spatial learning ability between young- and adult-age rats. J Exerc Rehabil 2017;13:381-386.

Jun Y, JiangTao X, YuanGui H, YongBin S, Jun Z, XiaoJun M, JianChun X, Heng $X$, XiaoXin Z, XinXiang X. Erythropoietin pre-treatment prevents cognitive impairments following status epilepticus in rats. Brain Res 2009;1282:57-66.

Jung SY, Kim DY. Treadmill exercise improves motor and memory functions in cerebral palsy rats through activation of PI3K-Akt pathway. J Exerc Rehabil 2017;13:136-142.

Kim SE, Han JH, Ko IG, Kim CJ, Kim KH. Alpha1-adrenergic receptor antagonist tamsulosin ameliorates aging-induced memory impairment by enhancing neurogenesis and suppressing apoptosis in the hippocampus of old-aged rats. Anim Cells Syst 2017;21:404-411.

Kim SE, Ko IG, Park CY, Shin MS, Kim CJ, Jee YS. Treadmill and wheel exercise alleviate lipopolysaccharide-induced short-term memory impairment by enhancing neuronal maturation in rats. Mol Med Rep 2013;7:31-36.

Kundrotiene J, Wägner A, Liljequist S. Fluoro-Jade and TUNEL staining as useful tools to identify ischemic brain damage following moderate extradural compression of sensorimotor cortex. Acta Neurobiol Exp (Wars) 2004;64:153-162.

Kuwana T, Newmeyer DD. Bcl-2-family proteins and the role of mitochondria in apoptosis. Curr Opin Cell Biol 2003;15:691-699.

Lee MH, Kim H, Kim SS, Lee TH, Lim BV, Chang HK, Jang MH, Shin MC, Shin MS, Kim CJ. Treadmill exercise suppresses ischemia-induced increment in apoptosis and cell proliferation in hippocampal dentate gyrus of gerbils. Life Sci 2003;73:2455-2465.

Lee SM, Kim BK, Kim TW, Ji ES, Choi HH. Music application alleviates short-term memory impairments through increasing cell proliferation in the hippocampus of valproic acid-induced autistic rat pups. J Exerc Rehabil 2016;12:148-155.

Lim BV, Shin MS, Lee JM, Seo JH. Treadmill exercise prevents GABAergic neuronal loss with suppression of neuronal activation in the pilocarpine-induced epileptic rats. J Exerc Rehabil 2015;11:80-86.

Liu YF, Gao F, Li XW, Jia RH, Meng XD, Zhao R, Jing YY, Wang Y, Jiang $W$. The anticonvulsant and neuroprotective effects of baicalin on pilocarpine-induced epileptic model in rats. Neurochem Res 2012;37:16701680.

Méndez-Armenta M, Nava-Ruíz C, Juárez-Rebollar D, RodríguezMartínez E, Gómez PY. Oxidative stress associated with neuronal apoptosis in experimental models of epilepsy. Oxid Med Cell Longev 2014;2014:293689.

Ming GL, Song H. Adult neurogenesis in the mammalian central nervous system. Annu Rev Neurosci 2005;28:223-250.

Narkilahti S, Pirttilä TJ, Lukasiuk K, Tuunanen J, Pitkänen A. Expression and activation of caspase 3 following status epilepticus in the rat. Eur J Neurosci 2003;18:1486-1496.

Parent JM, Elliott RC, Pleasure SJ, Barbaro NM, Lowenstein DH. Aberrant seizure-induced neurogenesis in experimental temporal lobe epilepsy. Ann Neurol 2006;59:81-91.

Reed CJ. Apoptosis and cancer: strategies for integrating programmed cell death. Semin Hematol 2000;37(4 Suppl 7):9-16.

Sarnat HB, Nochlin D, Born DE. Neuronal nuclear antigen (NeuN): a marker of neuronal maturation in early human fetal nervous system. Brain Dev 1998;20:88-94.

Schmidt-Hieber C, Jonas P, Bischofberger J. Enhanced synaptic plasticity in newly generated granule cells of the adult hippocampus. Nature 2004;429:184-187.

Scholl EA, Dudek FE, Ekstrand JJ. Neuronal degeneration is observed in multiple regions outside the hippocampus after lithium pilocarpineinduced status epilepticus in the immature rat. Neuroscience 2013;252: 45-59.

Setkowicz Z, Mazur A. Physical training decreases susceptibility to sub- 
sequent pilocarpine-induced seizures in the rat. Epilepsy Res 2006;71: 142-148.

Shin MS, Ko IG, Kim SE, Kim BK, Kim TS, Lee SH, Hwang DS, Kim CJ, Park JK, Lim BV. Treadmill exercise ameliorates symptoms of methimazole-induced hypothyroidism through enhancing neurogenesis and suppressing apoptosis in the hippocampus of rat pups. Int J Dev Neurosci 2013;31:214-223.

Sim YJ. Treadmill exercise alleviates impairment of spatial learning ability through enhancing cell proliferation in the streptozotocin-induced Alzheimer's disease rats. J Exerc Rehabil 2014;10:81-88.

Sim YJ, Kim SS, Kim JY, Shin MS, Kim CJ. Treadmill exercise improves short-term memory by suppressing ischemia-induced apoptosis of neuronal cells in gerbils. Neurosci Lett 2004;372:256-261.

Thom M, Eriksson S, Martinian L, Caboclo LO, McEvoy AW, Duncan JS, Sisodiya SM. Temporal lobe sclerosis associated with hippocampal sclerosis in temporal lobe epilepsy: neuropathological features. J Neuropathol Exp Neurol 2009;68:928-938.
Tyler AL, Mahoney JM, Richard GR, Holmes GL, Lenck-Santini PP, Scott RC. Functional network changes in hippocampal CA1 after status epilepticus predict spatial memory deficits in rats. J Neurosci 2012;32: 11365-11376

Weise J, Engelhorn T, Dörfler A, Aker S, Bähr M, Hufnagel A. Expression time course and spatial distribution of activated caspase-3 after experimental status epilepticus: contribution of delayed neuronal cell death to seizure-induced neuronal injury. Neurobiol Dis 2005;18:582-590.

Wolf HK, Buslei R, Schmidt-Kastner R, Schmidt-Kastner PK, Pietsch T, Wiestler OD, Blümcke I. NeuN: a useful neuronal marker for diagnostic histopathology. J Histochem Cytochem 1996;44:1167-1171.

Xu J, Wang S, Lin Y, Cao L, Wang R, Chi Z. Ghrelin protects against cell death of hippocampal neurons in pilocarpine-induced seizures in rats. Neurosci Lett 2009;453:58-61.

Zhang R, Yang G, Wang Q, Guo F, Wang H. Acylated ghrelin protects hippocampal neurons in pilocarpine-induced seizures of immature rats by inhibiting cell apoptosis. Mol Biol Rep 2013;40:51-58. 